\title{
Proposing a Gaming Language Analysis Procedure to Reveal Video Game Ideology through Ludic Linguistics
}

\author{
SF. Luthfie Arguby Purnomo* \\ Institut Agama Islam Negeri Surakarta \\ theluthfie@gmail.com \\ Khristianto \\ Universitas Muhammadiyah Purwokerto \\ Kristian.topz@gmail.com
}

DOI: https://doi.org/10.18326/rgt.v12i2.235-261

Corresponding Author*

\section{Submission Track:}

Received: 21-07-2019

Final Revision: 21-11-2019

Available online: 01-12-2019

\begin{abstract}
This study proposes a procedural analysis on the implementation of ludic linguistics to analyze gaming language with wordplay, the core of focus in ludic linguistics, as the point of departure. To formulate the procedural analysis, theories of language play by Crystal ideology of influence and ludonarrative model by Aarseth, wordplay in the gaming context by Paul, intended meaning level by Stiles, wordplay transmission by Winter-Froemel, game interface types by Stonehouse, and indexical storytelling by FernándezVara were applied as the theoretical foundation. To provide a vivid application of the proposed procedural analysis, wordplays appearing on game assets from Konami's Metal Gear Solid, Metal Gear Solid 2: Sons of Liberty, and Metal Gear Solid 3: Snake Eater were taken as examples of analysis. The fivestep procedure is able to show how wordplays in the gaming context are designed as mechanical cues to help gamers complete the games and as
\end{abstract}


narrative cues to help them comprehend the story. Moreover, this proposed procedure is able to indicate that the mechanical and narrative cues have a particular ideology of influence, which affects gamers in reacting and responding to particular problems presented by the games. The result of this study discloses future research on the roles of wordplays in the gaming context, signifying the importance of ludic linguistics as a bridge between language studies and game studies.

Keywords: Wordplay; Gaming Language; Ludic Linguistics; Game Studies; Metal Gear Solid

\section{INTRODUCTION}

Humans as Homo Ludens-playful creatures express their playfulness through games (Huizinga, 1949). Structurally games are classified into ludus, structured games, and paidia, unstructured games (Caillois, 1961). In playing games, humans make use of language to formulate rules, devise tactics, and achieve goals. Though game are diverse, in terms of types and how they are played, they share a common trait of the narrative. Rules, tactics, and goals are the game elements that contribute to the emergence of game narrative. Language intertwines itself with those elements to ensure that the game narratives are playful.

Perceiving how language is intertwined with playfulness, Crystal (1996) urges the necessity to study how humans use language to express their playfulness, which he calls ludic linguistics. Crystal (2001) emphasizes the relationship between language and playfulness in terms of language play for humorous purposes through wordplay as ludic rules. Since playfulness is not only related to humor and the development of games, concerns on how games are explainable from linguistics perspectives are taken into account. Before 
Crystal (2001) displays his concerns on the link between language and playfulness, Sudnow (1983) has indicated how the language used in games plays a significant role in establishing gameplay experience, further implying that gaming language has particular power in influencing gamers. Regarding this influence, Aarseth (1997) emphasizes on how human language and programming language are molded to instruct gamers to traverse games cybertextually. The traversing act by gamers indicates the presence of guidance or system of traversal within the game. Mäyrä (2008) argues that in games, language is a system that incorporates game rules and gameplays and provides meaningful playfulness for gamers. Due to its status as a system, an interaction commonly called human-computer interaction (HCI) occurs. Ensslin (2011) specifies this interaction in terms of how linguistics contributes in displaying the relationship between language use and ludic activities gamers perform. Concerning the linguistics implied by Ensslin (2011), Purnomo et al. (2016) emphasize the necessity to revisit ludic linguistics as argued by Crystal by focusing on two major elements it offers namely patterns and preferences. Patterns refer to how the game information is constructed while preferences to how gamers devise gaming strategies based on the information given. Departing from the combination of both, gaming identity or what they call as luden is able to be revealed.

The gap left by the aforementioned studies is how to incorporate the root of ludic linguistics, which is wordplay, in video game context to reveal how ideology of influence is transferred through the use of wordplays. This relationship might disclose a comprehension on the ideology particular games have and the influences they have upon gamers from language perspectives. To indicate how gaming languages have a link on the ideology of influence, 
this article employs language play by Crystal (2001), ideology of influence by Aarseth (1997), wordplay in the gaming context by Paul (2012), ludonarrative model by Aarseth (2012), intended meaning level by Stiles (1986), wordplay transmission by Winter-Froemel (2016), game interface types by Stonehouse (2014), and indexical storytelling by Fernández-Vara (2011). To display how these theories are integrable for an analysis, Konami's Metal Gear Solid, Metal Gear Solid 2: Sons of Liberty, and Metal Gear Solid 3: Snake Eater were used as an example. Expected results would indicate how the use of particular lingual expressions has distinctive purposes in directing or distracting the gamers from achieving in-game goals.

This study attempts to formulate a systemic tool of analysis, able to indicate how ludic linguistics is able to explain how wordplays, as its essence, contribute to the presence of ideology of influence. This tool will be beneficial for (a) linguists in comprehending the relationship between gaming language and the ideologies games have, (b) narrative designers in designing narrative cues or pathways to predict how the designed games are expected to trigger particular reactions and responses from the gamers, and (c) gamers in comprehending how language works in the gaming context. This study limits its scope on the phrase 'gaming language'. Gaming language might refer to computer codes, human languages delivered by computer codes, or human languages delivered by gamers to gamers. This study highlights the second with concerns over the first and the third to a particular extent. These three types of gaming languages, though being different in nature, share a common trait. They are constructed to indicate how game mechanics and narratives could contribute to the process of meaning making, from which gamers 
embrace ludic values or commonly called as playfulness. In cognitive perspectives as suggested by Lieberman (2014), playfulness is inseparable from one's creative cognitive style. This definition implies that the degree of a product of being playful or not relies on the individual's creativity through cognition upon the product. Wordplays in the gaming context are designed to be playful in a different sense from that of the non-gaming context. The playfulness of a game might be revealed through replayability, ability games have to attract gamers to play the games over and over (Newman, 2013). Besides limiting the study on the types of gaming language, this study specifies its range of gaming language by referring to the root of ludic linguistics, wordplay. Focusing on wordplay in the gaming context with consideration on its mechanical and narrative functions indicates a fusion between ludic linguistics and game studies, from which making sense is constructed in the sense that game mechanics and narratives are able to be analyzed from linguistics perspectives for uncovering the ideology of influence.

\section{RESEARCH METHOD}

This qualitative study employed Giddings' (2009) micro-ethnography approach for video game studies. This approach was selected since it focuses on the events resulting from the interaction between games and their gamers. This approach is linear to the essence of the ideology of influence and thereby employing this approach would generate a vivid picture of how wordplays, as the root of ludic linguistics, are constructed as such to influence the gamers in playing the games.

The data of this study were the game assets of Metal Gear Solid, Metal Gear Solid 2: Sons of Liberty, and Metal Gear Solid 3: Snake Eater comprising 
tutorials, items, skills/abilities, equipment, non-battle, pre-battle, in-battle, post-battle dialogues, music and song, and map. Metal Gear Solid was selected as the source of data since this game, labelled as one of the greatest video games of all time, laid the foundation of the so-called stealth genre, an action game, which instructs the gamers to complete any missions without being noticed. This game genre requires gamers to thoroughly consider every textual, visual, audial, and kinetic aspect to complete the game.

The researcher played Metal Gear Solid, Metal Gear Solid 2: Sons of Liberty, and Metal Gear Solid 3: Snake Eater, procured the game assets, stored and sorted them for analysis. The procured game assets comprise textual, visual, audial, and kinetic elements, from which a multimodal relationship is woven to generate meaning for the gamers. The game assets from Metal Gear Solid, Metal Gear Solid 2: Sons of Liberty, and Metal Gear Solid 3: Snake Eater were taken based on the perspectives of genotype, in which the game elements do not stand by themselves in constructing a meaning but they work together to signify the presence of game assets, from which meaning is perceived.

\section{RESULT \& DISCUSSION}

To make it more practical, the result of this study is presented in steps on how wordplays as the essence of ludic linguistics, ludonarrative, intended meaning level, interface design, indexical storytelling, and the ideology of influence are intertwined to generate an underlying particular meaning for games. Examples from Metal Gear Solid, Metal Gear Solid 2: Sons of Liberty, and Metal Gear Solid 3: Snake Eater are presented to better illustrate the steps. 


\section{Gaming language analysis procedures}

Kernel analysis

To reveal video game ideology with wordplays as the core focus, five steps of gaming language analysis are constructed. The first step is to reveal the kernel of game assets. Kernel is what cannot be omitted or replaced since its omission will totally change the narrative while the satellite is what can be replaced (Aarseth, 2012). Kernel in its simplest sense shares common traits as that of main idea of a text. The kernel of Spider Man, for instance, is spider bite, which turns Peter Parker into Spider Man. Without that bite, there would never be Spider Man. Thus, the kernel is spider biting. In the gaming context, kernel is uncoverable through the characteristic or the nature of game assets. The following table enlists regular game assets appearing on any game design and the kernel they are constructed from.

Table 1. Game Assets and Their Kernels

\begin{tabular}{ll|}
\hline Game Assets & Kernels \\
\hline Tutorial & Tutoring \\
Items & Effecting \\
Skills/Abilities & Effecting \\
Equipment & Effecting \\
Non-Battle Dialogues & Informing (in relation to the other game assets) \\
Pre-Battle Dialogues & Fighting/Indicating \\
In-Battle Dialogues & Fighting/Indicating \\
Post-Battle Dialogues & Informing (in relation to the other game assets) \\
Music and Song & Indicating \\
Map & Searching
\end{tabular}

Departing from understanding that each game asset has kernel, wordplays related to the kernel are uncoverable. In-game equipment is 
onomastically named to indicate an aesthetic relationship between mechanics and narrative elements. Chaff Grenade, one of iconic equipment in Metal Gear franchise, is named after seeds separated by the process of winnowing. This meaning aesthetically indicates its mechanical function, in which by throwing the grenade, Solid Snake becomes unnoticed from any visual, camera-based recording, separating him from the surveillance view. Interestingly when the grenade is thrown out, winnowing like sound effect and seed-like dots are heard and visualized on the screen. Chaff Grenade, as a part of the equipment, has an effecting kernel and thus the word 'chaff' is played for the gamers to think what effects it might have upon the player-controlled character, the computer-controlled proponent character, and the computer-controlled opponent characters.

\section{Intended meaning level analysis}

An analysis of the intended meaning level proceeds after the kernels are revealed. Intended meaning circumnavigates around attempts to recognize whether speakers disguise their hidden meaning through the use of particular expressions (Stiles, 1986). In the gaming context, cues or hints to complete a game might be explicitly or implicitly delivered to the gamers and it befalls to the gamers to decipher them. This condition implies that games actually speak to the gamers in a particular manner. Stiles (1986) classifies intended meaning into six levels namely level $0,1,2,3,4,5$. In this classification, the higher the level the deeper the intended meaning is hidden. Level 0 and 1 are literal, level 2 hint, level 3 manipulation, level 4 secret, and level 5 self-deception. In relation to the truth revealing functions, non-humorous wordplays in the 
gaming context are designed as such to deliver their intended meaning to the gamers by requesting them to perceive the meaning of wordplays, not the way it is presented.

In the case of Chaff Grenade, if a description on the grenade usage and function is not existent, the intended meaning on the wordplay is of level two since recognizing the usage and function of Chaff Grenade is not only obtainable from deciphering the word 'Chaff' but also from trial and error by the gamers. In the game, Chaff Grenade is presented along with its description and thus making the wordplay falls into level zero, literal intended meaning. To give a better understanding of how Stiles' (1986) intended meaning level works in the gaming context, a table is presented as follow:

Table 2. Intended Meaning Level Classification

\begin{tabular}{|c|c|c|}
\hline $\begin{array}{c}\text { Intended Meaning } \\
\text { Level }\end{array}$ & Name & Description \\
\hline Level 0 & Literal & $\begin{array}{l}\text { No hidden intended meaning } \\
\text { Intended meaning is explicitly delivered } \\
\text { through various assistive menu } \\
\text { containing explanation, description, or } \\
\text { procedure }\end{array}$ \\
\hline Level 1 & Literal & $\begin{array}{l}\text { No hidden intended meaning } \\
\text { Intended meaning is explicitly articulated } \\
\text { without the help of assistive menu }\end{array}$ \\
\hline Level 2 & Hint & $\begin{array}{l}\text { Intended meaning is hidden } \\
\text { Gamers are not required to reveal the } \\
\text { intended meaning but revealing it } \\
\text { discloses possibilities to play the game } \\
\text { efficiently and effectively }\end{array}$ \\
\hline Level 3 & Manipulation & $\begin{array}{l}\text { Intended meaning is hidden } \\
\text { Gamers are required to reveal the } \\
\text { intended meaning to proceed to next } \\
\text { missions or stages }\end{array}$ \\
\hline
\end{tabular}


Level 4

Secret

Level 5
SelfDeception
If gamers fail to reveal the intended meaning, the game will provide assistance

Intended meaning is hidden in the form of cheat

Gamers need to perform specific actions like button pressing, run special program over the game or download extra content to reveal the intended meaning Intended meaning is hidden in glitch or bug due to errors in the game Gamers do not perform specific procedures to reveal the intended meaning since gamers accidentally bump over the glitches or bugs

As seen from the table, that the criteria employed to indicate intended meaning level are game-to-gamer centric indicates that game acts as an addresser while gamers as an addressee. This addressing relationship points out that both attempt to communicate through a language with specific features. In the case of 'chaff', that its level of intended meaning is of level zero is not only indicated by the criteria of its level but also the way the played word is presented, wordplay transmission, the next step of the analysis.

\section{Wordplay transmission analysis}

Wordplays require media to transmit their meaning, implying that different media generates different approaches to comprehend the wordplays. Winter-Froemel (2016) classifies three types of wordplay transmission namely phonic, graphic, and combination of both. In relation to intended meaning, the attribution of image, sound, and motion on the played words signify different levels of intended meaning. In the case of Chaff Grenade, this weapon is 
visualized and sound-effected and thereby assisting gamers in recognizing the mechanical function of the grenade. The presence of these visual and audial attributes is also another proof that 'chaff', played on Chaff Grenade, is of level zero in intended meaning. In the gaming context, visual and audial attributes are not only the concerns but the way the attributes are displayed is also taken into concerns. Video games, like any other computer programs, utilize interface to allow gamers to interact with the game elements via visual and audial attributes.

Four types of interfaces video games utilize are diegetic, meta-diegetic, spatial, and non-diegetic (Stonehouse, 2014). On the diegetic interface, the interface is blended within the narrative and game environment. In a simple understanding, the diegetic interface does not explicitly display the interface and thus making the immersion level of gamers high. Meta-diegetic shares similar traits like diegetic in which the interface is not explicitly displayed. What makes the two different is that in meta-diegetic, the interface is designed in a 2D plane. If gamers want to chat with in-game avatars, for instance, the interface displayed on screen might take a real-life communication tool instead of symbols. The spatial interface relies on symbols to indicate where game avatars should go so that gamers would not miss the intended direction. The immersion level of this interface is lower than diegetic and meta-diegetic. The lowest in immersion among the four is non-diegetic in which movements, equipment, and other game elements are symbolized and thereby reducing the immersive level of gamers in the narrative. Visual and audial attributes attached to the wordplay, in the gaming context, are dependent on these interface types. If immersion is graded like that of intended meaning, a 
relationship between wordplay transmission, interface, and intended meaning level will be visible as follow:

Table 3. Wordplay Transmission Scales (Mechanical Functions)

\begin{tabular}{|l|l|l|c|}
\hline Interface Types & Immersion Level & Wordplay Transmission & $\begin{array}{c}\text { Intended } \\
\text { Meaning Level }\end{array}$ \\
\hline Diegetic & High & None & 4 \\
& & Visual & 3 \\
& & Audial & 2 \\
& & Audial-Visual & 1 \\
Meta-Diegetic & \multirow{2}{*}{ Medium } & Visual-Audial & 0 \\
& & None & 4 \\
& & Visual & 3 \\
& & Audial & 2 \\
Spatial & Audial-Visual & 1 \\
& \multirow{3}{*}{ Fair } & Visual-Audial & 0 \\
& & None & 4 \\
& & Visual & 3 \\
Non-Diegetic & Low & Audial & 2 \\
& & Audial-Visual & 1 \\
& & Visual-Audial & 0 \\
& & None & 4 \\
& & Visual & 3 \\
& & Audial & 2 \\
& & Audial-Visual & 1 \\
& & Visual-Audial & 0
\end{tabular}

Intended meaning level 5 is not included in the scale since level 5 in the game deals with glitches and bugs, which indicate the presence of in-game mechanical errors and troubles. Audial-Visual and Visual-Audial refer to the cooperative relation both transmissions have with the first word being more emphasized than the second. As seen from the table, wordplays transmitted in a more detailed fashion have a more literal intended meaning. In addition, the 
more diegetic an interface has in transmitting the wordplays, the higher the immersion level is. In Chaff Grenade case, the immersion level is low and the intended meaning is of level zero. This low-zero combination points out that Chaff Grenade is designed to have a direct influence on the gamers so that they might engage its mechanical functions in a responsive manner.

In the context of narrative functions, wordplay transmission is delivered in regard to the storytelling or story building types the games have. Fernández-Vara (2011) proposes indexical storytelling, a story told through indications or indices, terms borrowed from Peircean sign philosophy. Indexical storytelling claims that stories in games are not only intended to tell something to the gamers but also to indicate the gamers to do something. In Revolver Ocelot case, for instance, the lines said by the gunman are not intended only to tell that he is an experienced Colt user but also to indicate that the gun has only six bullets and it requires time to reload. The first function is what Fernández-Vara (2011) refers to as 'what happened;' the second, what should be done. In brief, the former is better termed event and the second, action. In event, the story attempts to immerse gamers in 'telling' while in action, the immersion lies on 'building'. These different types of immersion signify a different level of engagement, how gamers are exposed to particular games or game elements (McMahan, 2003). In telling, gamers are required to connect past and present events to predict and analyze what event will be occurring in the future of the controlled character. Meanwhile, in building, gamers have to connect cues hidden or exposed in the game environment. In regard to wordplays and their transmissions, telling and building also share the same transmissions as what mechanical functions have. 
Table 4. Wordplay Transmission Scales (Narrative Functions)

\begin{tabular}{|l|l|l|l|}
\hline $\begin{array}{l}\text { Indexical Storytelling } \\
\text { Types }\end{array}$ & Immersion & Wordplay & Inte \\
& Level & Transmission \\
& & \\
& & & Me \\
& & & ani \\
& & ng \\
& & & Lev \\
& & & el \\
\hline Event & Telling & None & 4 \\
& & Visual & 3 \\
& & Audial & 2 \\
& & Audial-Visual & 1 \\
Action & & Visual-Audial & 0 \\
& Building & None & 4 \\
& & Visual & 3 \\
& & Audial & 2 \\
& & Audial-Visual & 1 \\
& & Visual-Audial & 0
\end{tabular}

In the case of Chaff Grenade, the indexical storytelling is action and thus building becomes the focus of the played word. As it falls into building, gamers are asked to reveal the cues of the grenade functions. To do so, gamers could rely on themselves to know how the played word is transmitted, whether the word is aided by visual, audial, both, or none. The way the word is transmitted, as discussed before, is connected to the intended meaning level.

\section{Ideology of influence analysis}

The analysis on wordplay transmission encompassing both mechanical and narrative functions are brought together along with the analysis on kernel and intended meaning level to reveal the ideology of influence principle that 
the analyzed played word has. The ideology of influence falls into two principles of delivery namely metamorphosis and anamorphosis (Aarseth, 1997). The former attempts to influence gamers in a literal way, implying that gamers are free to configure any strategies with the existing features of the games to accomplish particular goals. Meanwhile, the latter demands gamers to traverse the games in a specific way to complete certain objectives, hidden from the literal ones. In the context of wordplays, this specific traversal mode is also required. This is due to the fact that wordplay might be utilized to function as a veiled speech and a safe criticism (Ahl, 1984), to which politics is primarily attached (Mitsis and Ziogas, 2016). Wordplay might also be aesthetically employed to strengthen the poetic sides of art or the witty sides of fictional characters (Mahood, 2003; Louden, 1995). To provide a clear relationship among each step, the analysis is delivered through a hierarchical process chart:

Chart 1. Wordplay Analysis Example

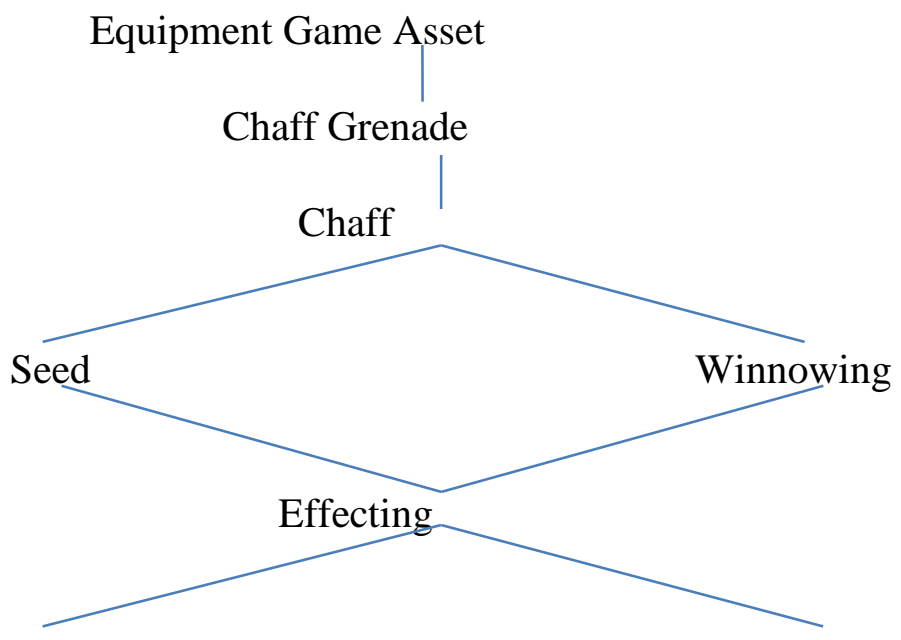



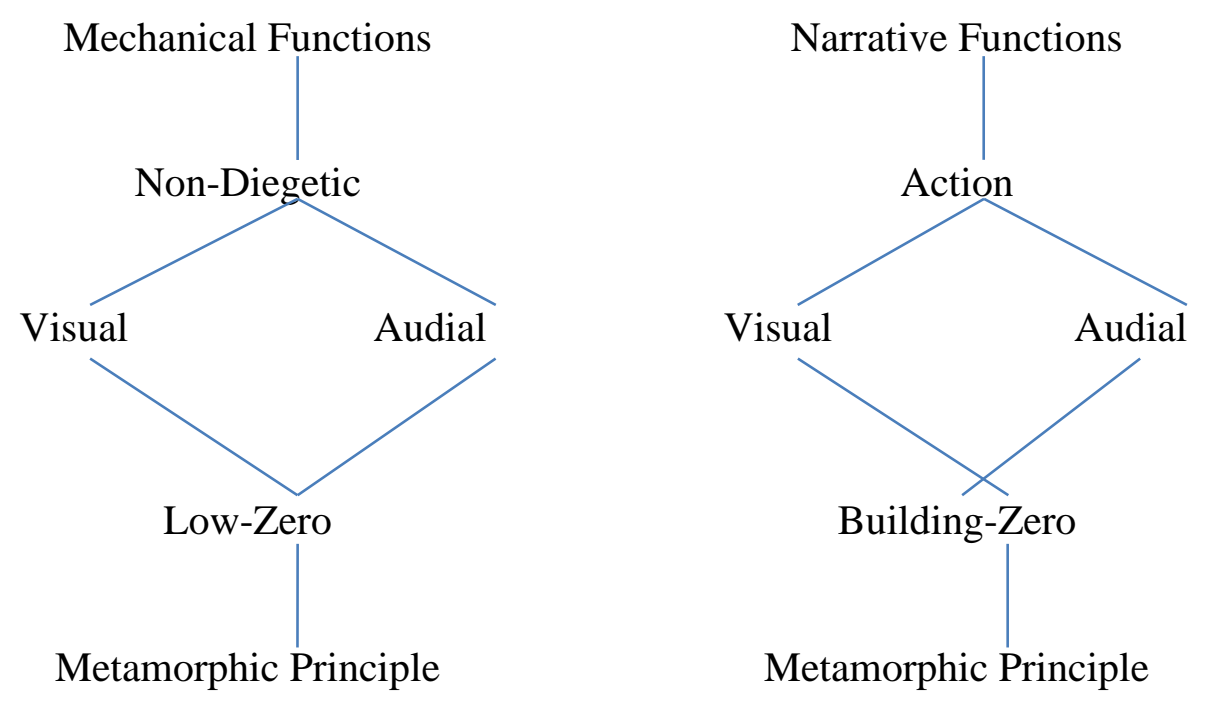

As seen from the chart above, the word played in Chaff Grenade is 'chaff'. This word has an effecting kernel since it belongs to the equipment game asset. The effecting kernel occurs on the mechanical functions of the word only. The mechanics are non-diegetically displayed with visual and audial aids. These aids are the graphic and phonic realization of the meaning behind 'chaff', semantically related to 'seed' and 'winnowing'. Since the meaning is realized through the use of non-diegetic interfaced visual and audial aids, 'chaff' in Chaff Grenade is low in immersion and zero in intended meaning. This condition indicates that the metamorphic principle is applied in delivering ideology of influence, meaning that the word 'chaff' is not designed to be deciphered by the gamers. What occurs in the case of 'chaff', which emphasizes on the mechanism of using the equipment, is a type of equipment naming in military games. A different case might occur when the equipment naming is intended for a role-playing game (RPG) with all its derivative genres. 
Chaff in its narrative functions, as seen from the above chart, focuses on action indexical storytelling. It implies, as suggested before, that the played word 'chaff' is not intended to provide information regarding the story occurring before and after the introduction of 'chaff'. Chaff is indicated to lead the gamers to perform particular actions through the controlled character. To perform this action, in the case of 'chaff', the indication is delivered in intended meaning level zero, meaning that the cues to operate the grenade are explicitly delivered or metamorphically delivered. In the context of ludo-narrative, the focus on mechanical function 'chaff' indicates that the mechanics of Chaff Grenade builds the weapon's narrative. When a game asset relies on mechanical functions to establish its narrative, it points out that the game asset is not story-related but gameplay-related. When game assets dominantly have more focus on mechanics than narrative, it implies that the genre the game has is gameplay-driven. On the other hand, the game genre is narrative-driven genre when narrative functions dominate the game assets. If a game has a balanced portion for both functions, the genre is gameplay and narrativedriven. This classification of gameplay, narrative, and gameplay-narrative conforms to the theory of Clearwater (2011) on game genre. The following table might illustrate how the ideology of influence principles are intertwined with mechanical and narrative functions: 
Table 5. Ideology of Influence and Mechanical-Narrative Functions

\begin{tabular}{|l|l|l|l|l|}
\hline & \multicolumn{2}{|l|}{$\begin{array}{l}\text { Mechanical } \\
\text { Functions }\end{array}$} & \multicolumn{2}{l|}{$\begin{array}{l}\text { Narrative } \\
\text { Functions }\end{array}$} \\
\cline { 2 - 6 } & Metamorphic Principle & $\begin{array}{l}\text { Anamorphic } \\
\text { Principle }\end{array}$ & $\begin{array}{l}\text { Metamorphic } \\
\text { Principle }\end{array}$ & $\begin{array}{l}\text { Anamorphic } \\
\text { Principle }\end{array}$ \\
\hline Dominance & Superior & $\mathrm{x}$ & Inferior & $\mathrm{x}$ \\
Relationship & Superior & $\mathrm{x}$ & $\mathrm{x}$ & Inferior \\
& $\mathrm{x}$ & Superior & $\mathrm{x}$ & Inferior \\
& $\mathrm{x}$ & Superior & Inferior & $\mathrm{x}$ \\
& $\mathrm{Inferior}$ & $\mathrm{x}$ & Superior & $\mathrm{x}$ \\
& $\mathrm{Inferior}$ & $\mathrm{x}$ & $\mathrm{x}$ & Superior \\
$\mathrm{x}$ & Inferior & $\mathrm{x}$ & Superior \\
$\mathrm{x}$ & Inferior & Superior & $\mathrm{x}$ \\
\hline
\end{tabular}

The table shows that two types of dominance relationship are existent namely superior and inferior. Superior dominance means that particular ideology of influence dominates more than the other in mechanical or narrative functions. If metamorphic and anamorphic principles are superior on mechanical functions, it implies that the game focuses primarily on gameplay with a different manner of presentations. Gameplay delivered by metamorphic principle allows gamers to play the game without even learning it and vice versa for anamorphic principle. On the other hand, if metamorphic and anamorphic principles are superior in narrative functions, the game focus is on its gamestory (narrative). Gamestory narrated through metamorphic principle indicates that the story is presented in a conventional formula, in which gamers are not required to perform a specific method to comprehend the story. In an anarmophic principle delivered gamestory, a specific method to traverse the 
story is a requirement for the gamers to fulfill if they attempt to comprehend the story.

Gameplay and gamestory are intermingled in video games and thus, signifying that they are reliant to one another, meaning that gamers need to perform particular action to advance the story. In the context of metamorphosis, the action might be freely or conventionally exercised while in anamorphosis, since the action is hidden, the first thing gamers have to do is to reveal how to do it by connecting all the cues presented through wordplays. In Metal Gear Solid, just like other AAA (triple A) game with role-playing elements, has what is called as secrets or Easter Eggs. These secrets are not delivered on the literal level of the intended meaning. In some cases, the cues to reveal the secrets are not visually or audially accompanied. Hideo Kojima, the creator of this franchise, is fond of employing references to famous films and games in his games. One of the films Kojima refers constantly to is the James Bond series. In Metal Gear Solid: Integral, the expanded version of Metal Gear Solid, if the gamers are aware of this James Bond reference, the gamers might be prompted to seek out for secrets by deciphering anything related to James Bond and one of the game features which might provoke the gamers to experiment is the Codec. This communication device is operated through frequency searching. It asks gamers to search for the correct frequency in five-digit inputs starting with 140. The last two digits disclose chances for gamers to experiment. If the gamers are aware of the James Bond references in the games in forms of themes, motifs, and plots, they might try to input 140.07. 007 is James Bond's iconic number and by inputting it, the gamers will obtain a secret in the form of the game staff commentaries in Japanese, containing some of the game production agenda. This example signifies how 
anamorphosis influences the gamers to connect and relate all the cues to uncover the hidden action and story.

\section{Wordplay function analysis}

The final step of this procedural analysis on gaming language is to identify how the functions of wordplay in the gaming context are realized through the played words. Wordplay in the gaming context circumnavigates on rhetorical criticism, focusing on how particular artefacts weave a relationship with the rhetors, audiences, situations, and messages (Foss, 2017). This rhetorical nature of wordplay in video games implies the positioning and functioning of words are in regard to the gamers, the symbols the games depict, and the influences the words have upon gamers. Departing from this rhetorical nature, wordplay in the gaming context takes a different form and function from those of wordplay found in ludic linguistics or recreational linguistics yet serving the same purpose of playfulness. Paul (2012) states that wordplay in the gaming context has three primary functions namely facilitating analysis of how games persuade, creating identifications, and circulating meanings.

A descriptive analysis takes place to explain how wordplay functions namely persuasion, identification, and meaning circulation are embodied and exercised through the played word. In the case of 'chaff', since the word is attached to a grenade, the persuasion it has toward gamers is that it is used to explode something in a far range usage. Recognizing the function, gamers are persuaded to use Chaff Grenade when a surveillance problem occurs. Two types of persuasion are existent namely compulsive and resistible persuasion. In compulsive persuasion, the problems gamers meet have only one solution 
and thereby in wordplay context, gamers have to locate and decipher the played word and its intended meaning. Meanhwile, resistible persuasion frees gamers from solving the problems they meet with or without comprehending the wordplay. 'Chaff' is the only solution for a surveillance problem since without having this grenade, Solid Snake will be detected by the surveillance camera and this condition makes the persuasion falls into a compulsive persuasion. If this type of persuasion 'chaff' case displays is wrapped in the metamorphic principle, it indicates that 'chaff' as the played word functions as an aesthetic attribute only. If the compulsive persuasion is delivered through an anamorphic principle, it points out that the wordplay works as a functional attribute. In Metal Gear Solid, this type of persuasion is found from the aforementioned case of Psycho Mantis. Another case showing compulsive persuasion in anamorphic principle appears on Metal Gear Solid 3: Snake Eater when Snake has to face The Sorrow. This boss takes the shape of a ghost. Snake cannot kill him but he can kill Snake. If the gamers are observant, they will notice that The Sorrow keeps on saying lines with the kernel 'returning' like 'go back to your own world', 'wake up', 'now you will know the sorrow of those whose lives you have ended'. These lines are supported by visuals of the characters Snake has killed before, signifying the kernel 'returning'. The solution to defeating The Sorrow lies on allowing Snake to die first and taking a pill called Revival Pill to return Snake to life. Doing so, The Sorrow will be defeated.

Identification comes after persuasion. The difference between persuasion and identification lies on the target or addressee. In persuasion, what appears on the game forces the gamers to react and respond while identification deals with how gamers cognitively perform a mechanical adjustment through button pressing, difficulty setting, or game configuration 
as a physical embodiment of reaction and response. Since a mechanical adjustment is required, it implies that the adjusment might not only be singular in method but plural. In 'chaff' case, the identification is singular since all the gamers need to is to browse for the grenade and throw it off without configuring any mechanical adjusment. Identification might also take in the forms of button pressing.

In Metal Gear Solid 2: Sons of Liberty, gamers have to face a woman boss by the name Fortune. Her name signifies her combat ability. Any shots directed to her will be missed. Any traps set for her will be malfunctioning. Her luck is her combat ability. Fortune's lines are in line with her name meaning. 'Maybe you can give me death?', 'My name is Fortune. Lucky in war and nothing else', 'And without death to call my own', 'Hurry, kill me please' are the lines which indicate that nothing can harm Fortune. If nothing can harm her, it means the only way to complete the fight is to escape or to survive. Since the fight takes place in a locked room, the only option gamers have is to survive. This method of completing the fight, besides being indicated by a visual aid in a form of a scene, showing Raiden hiding behind a giant crate and jumping to avoid Fortune's attack, which destroys the crate. Identifying this, the adjusments made are plural in terms of hiding and jumping action. The plural identification comes from the arbitrariness games have in choosing which crates to hide behind and to which direction gamers move Raiden.

After the persuasion and identification functions of the analyzed wordplay were revealed, meaning circulation takes place. In meaning circulation, the analysis focuses on summarizing how the meaning carried by the played word circulates around the kernel of the game narrative and 
mechanics. In Metal Gear Solid, the game narrative kernel is Metal Gear, a gigantic nuclear launching bipedal robot or mecha and the game mechanics kernel is stealth action. In the case of 'chaff', the word is related to the game narrative and mechanics kernel since the meaning of 'chaff' is also related to missile deployment and 'chaff' is utilized to make the thrower remain unseen in action. This type of meaning circulation, where the played word is connected to the kernels of game narratives and mechanics, is called componential. The following table provides the types of meaning circulation:

Table 6. Meaning Circulation Types

\begin{tabular}{|l|l|l|}
\hline Types & $\begin{array}{l}\text { Played Word and } \\
\text { Game Narratives }\end{array}$ & $\begin{array}{l}\text { Played Word and } \\
\text { Game Mechanics }\end{array}$ \\
\hline Componential & Connected & Connected \\
Constituential & Connected & Not Connected \\
Elemental & Not Connected & Connected \\
Ingrediential & Not Connected & Not Connected
\end{tabular}

The presence of componential circulation indicates that the played word is substantial in terms of game narratives and mechanics. In the case of 'chaff', gamers will have to rely on it from the beginning to the end of the games since surveillance is one of the primary issues gamers have to face. Different from componential circulation, constituential circulation signifies that the played word plays a key role in comprehending the flow of the game story. The mobile weapon Metal Gear is visually depicted to resemble that of T-Rex, from which a narrative of the food chain is constructed, thereby characters controlled and fought by gamers in the game are based on animal, indicating that T-Rex stands on the top of the food chain. Moreover, the names 
of the bosses are related to the word gear, weapons. Revolver Ocelot, Sniper Wolf, and Vulcan Raven with exception being Liquid Snake since he fights with a variety of weapons bear them the names of weapons. This focus on weapon functions as a hint for game mechanics, from which gamers could take advantage. This weapon-related name is the example of elemental circulation. The last circulation, ingredential, as the name implies, it refers to trivial or promotional function. As discussed before, most games with franchise have what is called Easter Egg. This Easter Egg primarily functions as a tool to evoke fun and nostalgia. The presence of Konami games, Policenauts, Mario statuette, Yoshi statuette, adult model posters and other Easter Eggs in Metal Gear franchise serve ingredential circulation when related to particular played words.

\section{CONCLUSION}

Ludic linguistics roots from wordplays for humorous purposes, implying that wordplays through their construction have the power to influence its recipients to react and respond to the messages the wordplays bear. This concept is applicable to explain how gaming language works by highlighting the functions of wordplays in the gaming context. Those functions are facilitating analysis of how games persuade, creating identifications, and circulating meanings. These three functions are intertwined with ideology of influence, how game elements influence gamers in taking decisions to solve particular problems or challenges the games offer. In delivering ideology of influence, two principles are known namely metamorphosis, a literal traversal of delivering ideology of influence, and anamorphosis, a specific traversal. 
In explaining how gaming language works in regard to how wordplays along with their functions contribute to the emergence of ideology of influence in games, five proposed steps should be taken. First, kernel analysis on game assets is exercised on the analyzed wordplay to reveal the primary message of the game asset in regard to the wordplay. Second, after the kernel is revealed, the intended meaning level of the wordplay is revealed. Third, in tandem with intended meaning analysis, wordplay transmission is analyzed to reveal how the way the wordplay is presented influences its intended meaning. Fourth, ideology of influence is revealed through a tree chart to easily notice the causal relationship previous steps have toward the emergence of particular ideology. Fifth, a descriptive analysis on how the wordplay serves its three primary functions is exercised in regard to the ideology of influence.

\section{REFERENCES}

Aarseth, E. J. (1997). Cybertext: Perspectives on ergodic literature. JHU Press.

Aarseth, E. (2012, May). A narrative theory of games. In Proceedings of the international conference on the foundations of digital Games (pp. 129133). ACM.

Ahl, F. (1984). The art of safe criticism in Greece and Rome. The American Journal of Philology, 105(2), 174-208.

Caillois, R. (1961). Man, play and games (M. Barash, Trans.). Champaign: University of Illinois Press.(Original work published in 1958).

Clearwater, D. (2011). What defines video game genre? Thinking about genre study after the great divide. Loading..., 5(8). 
Crystal, D. (1996). Playing with linguistic problems: From Orwell to Plato and back again. Georgetown University Round Table on Languages and Linguistics (GURT) 1996: Linguistics, Language Acquisition, and Language Variation: Current Trends and Future Prospects, 5.

Crystal, D. (2001). Language play. University of Chicago Press.

Ensslin, A. (2011). The language of gaming. Macmillan International Higher Education.

Fernández-Vara, C. (2011). Game spaces speak volumes: Indexical storytelling. In Proceedings of DiGRA 2011 Conference: Think Design Play.

Foss, S. K. (2017). Rhetorical criticism: Exploration and practice. Waveland Press.

Giddings, S. (2009). Events and collusions: A glossary for the microethnography of video game play. Games and Culture, 4(2), 144157.

Huizinga, J. (1949). Homo ludens: A study of the play-element in our culture. Routledge \& Kegan Paul.

Lieberman, J. N. (2014). Playfulness: Its relationship to imagination and creativity. Academic Press.

Louden, B. (1995). Categories of Homeric wordplay. Transactions of the American Philological Association (1974-), 125, 27-46.

Mäyrä, F. (2008). An introduction to game studies. Sage Publications Ltd.

Mahood, M. M. (2003). Shakespeare's wordplay. Routledge.

McMahan, A. (2003). Immersion, engagement and presence. The video game theory reader, 67, 86 . 
Mitsis, P., \& Ziogas, I. (Eds.). (2016). Wordplay and Powerplay in Latin Poetry (Vol. 36). Walter de Gruyter GmbH \& Co KG.

Newman, J. (2013). Videogames. London: Routledge.

Paul, C. A. (2012). Wordplay and the discourse of video games: Analyzing words, design, and play. Routledge.

Purnomo, S. L. A., Nababan, N., Santosa, R., \& Kristina, D. (2016). Game time: Revisiting ludic linguistics for video game analysis. PROSIDING PRASASTI, 689-694.

Stiles, W. B. (1986). Levels of intended meaning of utterances. British Journal of Clinical Psychology, 25(3), 213-222.

Stonehouse, A. (2014). User interface design in video games. Retrieved August, 3, 2014.

Sudnow, D. (1983). Pilgrim in the Microworld. New York: Warner Books.

Winter-Froemel, E. (2016). Approaching wordplay. Crossing languages to play with words. Multidisciplinary perspectives, 11-46. 